\title{
粚
}

\section{Spreuke 9: struktuur en funksie}

\author{
H.J.M. (Hans) van Deventer
}

Vakgroep Teologie

Skool vir Basiese Wetenskappe

Vanderbijlparkkampus

Noordwes-Universiteit

VANDERBIJLPARK

E-pos: bybhjmvd@puk.ac.za

\begin{abstract}
Proverbs 9: structure and function

This article focuses on Proverbs 9 - a chapter that concludes the introductory section of the book of Proverbs. It is indicated that the chiastic structure that can be discerned in this chapter fulfils an important function as regards the understanding and unity of the book. Proverbs 9 not only refers back to the first chapter of the book, but also relates to the last chapter of the book of Proverbs.
\end{abstract}

\section{Opsomming}

\section{Spreuke 9: struktuur en funksie}

Hierdie artikel fokus op Spreuke 9, 'n hoofstuk wat die inleidende deel van die boek Spreuke afsluit. Daar word aangetoon dat die chiastiese struktuur wat in hierdie hoofstuk onderskei kan word, 'n belangrike funksie vervul met betrekking tot die verstaan en eenheid van die boek. Spreuke 9 gryp nie net terug na die eerste hoofstuk van die boek nie, maar hou ook verband met die laaste hoofstuk van die boek Spreuke.

\section{Inleiding}

Sedert die middel van die twintigste eeu het die insigte van Ferdinand de Saussure aangaande die funksies van taal 'n groot invloed uitgeoefen op die denke in die taal- en literatuurwetenskappe. Eagleton (1983:96) wys daarop dat literêre strukturalisme 'n uitvloeisel was van die toepassing van De Saussure se idees aangaande taal - ook op literêre tekste. Die ontwikkeling van literêre strukturalisme in die literatuurwetenskap het ook 'n invloed op die Bybelwetenskappe gehad. Barton (1996:105-106) bied die volgende 
twee redes aan vir die goeie ontvangs van strukturalistiese insigte binne die Bybelwetenskappe:

- 'n teleurstelling in die (gebrek aan) resultate van die tradisionele histories-kritiese benadering tot die Bybelteks; en

- die insig dat navorsing in die Bybelwetenskappe nouer kan aansluit by die resultate van navorsers op die terrein van die algemene literatuurwetenskap.

James Muilenburg het in 1968 in sy presidensiële rede voor die Society of Biblical Literature retoriese kritiek uitgestip as een van die moontlike weë in die Bybelwetenskappe wat enersyds kon breek met die uitsluitlik historiese benadering, en andersyds kon voortbou op die ontwikkeling in die algemene literatuurwetenskap (vgl. Muilenburg, 1969). Een van sy studente, Phyllis Trible, het hierdie idees uitgebou en in die middel van die negentigerjare van die vorige eeu steeds die doel van retoriese kritiek omskryf as die artikulasie van die wisselwerking tussen die vorm en inhoud van 'n teks, waardeur betekenis ontsluit word (Trible, 1994:122).

Hierdie artikel sluit aan by die gedagte dat die vorm en inhoud van 'n teks bydra tot betekenis. Die fokus val hier op die boek Spreuke 1 en meer spesifiek, Spreuke 9. Spreuke 9 word ontleed met die oog op die daarstel van 'n struktuurvoorstel vir die betrokke hoofstuk, asook 'n voorstel rondom die eenheid van die boek wat hieruit mag voortspruit. Vir hierdie doel word gebruik gemaak van die insigte aangaande chiasmus as literêre tegniek, soos dit in die Bybelse literatuur na vore kom. ${ }^{2}$ In die boek Spreuke staan hoofstuk 9 aan die einde van die deel wat algemeen aanvaar word as 'n latere toevoeging tot die res van die boek. Dit dien ook as inleidende deel tot die boek in sy huidige vorm (Whybray, 1995:62). Hierdie inleiding beslaan Spreuke 1-9 en word gekenmerk deur langer didaktiese gedigte (leerdigte). Hierdie langer gedigte vorm 'n kontras met die aforismes (kort gesegdes) wat Spreuke 10-303 hoofsaaklik kenmerk

1 Whybray (1995:34) wys op die voetspoor van Von Rad ook op die belang van die wisselwerking tussen vorm en inhoud as dit kom by die verstaan van die boek Spreuke.

$2 \quad$ Hier word veral van die bydraes van Radday (1981) en Watson (1981) gebruik gemaak. Vergelyk Welch (1981) vir bydraes aangaande die gebruik van hierdie literêre tegniek in ander literatuur uit die antieke tyd.

3 In Spreuke 30 is 'n oorgang te bemerk en hierdie hoofstuk word dikwels (as gevolg van die opskrif in 30:1) eerder saam met Spreuke 31 gegroepeer. Die inhoud en samestelling van hoofstuk 30 is egter baie divers en Whybray 
(Fox, 2000:44). Alhoewel daar in hierdie gedeelte van die boek (hoofstukke 10-30) wel enkele uitsonderings is, ${ }^{4}$ is dit eers weer in Spreuke 31 waar didaktiese gedigte van 'n soortgelyke lengte as dié in die inleidende gedeelte aangetref word. 5

In hierdie artikel word eers gelet op die bestaande konsensus 6 onder Ou-Testamentici met betrekking tot die samestelling van die boek Spreuke. Die aandag word voorts bepaal by die struktuur van Spreuke 9 en dan word na chiasmus as literêre tegniek verwys om ten slotte enkele gevolgtrekkings te maak rakende die struktuur en eenheid van die boek in die geheel.

\section{Die groepering van die wyshede in Spreuke}

In hierdie afdeling word kortliks gelet op die breë konsensus wat onder Ou-Testamentici bestaan met betrekking tot die rangskikking van materiaal in die boek Spreuke. Dit word oor die algemeen aanvaar dat die boek Spreuke die produk is van die versameling van diverse wyshede wat oor 'n lang tyd ontstaan het. Whybray (1994a:158) som die ontstaansproses soos volg op:

... the book is composed of a number of originally distinct sections, of which the majority have had more or less complicated histories of their own. These sections developed in different social circles and at different times, and comprise a number of quite different literary forms.

Die naam van Salomo word op drie plekke $(1: 1 ; 10: 1 ; 25: 1)$ as outeur aan die boek of onderafdelings daarvan gekoppel. Clifford (1999:3) wys daarop dat dit in die Joodse tradisie die gebruik was om die wysheidsliteratuur met Salomo te verbind en dat nie al die spreuke in hierdie versamelings noodwendig dateer uit die tiende

(1995:86) merk in hierdie verband op dat die meeste kommentators, ten spyte van 'n tweedeling wat hulle in die hoofstuk herken, erken dat die hoofstuk nie 'n tematiese of strukturele eenheid vertoon nie en "may have been assembled from a number of sources". Om hierdie redes word hoofstuk 30 hier saam met Spreuke 10-29 gegroepeer.

4 Vgl. veral die getalle-spreuke in 30:18-20, 21-23, 24-28 en 29-31.

$5 \quad$ Meinhold (1991:43) beskou Spreuke 1-9 saam met Spreuke 31:10-31 as die raamwerk van die boek.

6 Daar sal nooit volledige konsensus onder navorsers bestaan nie. Vir die doeleindes van hierdie artikel is dit nie nodig om die verskillende nuanses van navorsers hier weer te gee nie. Whybray (1995) se werk bied 'n goeie oorsig van die verskillende sienings wat bestaan. 
eeu vHE7 nie. Uit Spreuke 25:1 lei Clifford (1999:219) wel af dat daar in die agtste eeu vHE 'n versameling spreuke "van Salomo" was $^{8}$ wat deur die hervormingskoning Hiskia verder uitgebrei is. Uit meer behoudende teologiese kringe meld Farmer (1991:18) ook dat verwysings na Salomo nie aan outeurskap verbind hoef te word nie, maar eerder dui op 'n bepaalde soort gesegde, alhoewel die ontdekking van soortgelyke materiaal uit Egiptiese, Babiloniese en Fenisiese bronne wel daarop dui dat hierdie gedagtegang reeds gedurende die tweede millennium vHE bekend was (Kidner, 1964:25-27).

Verklaarders gebruik steeds die "opskrifte" by die verskillende versamelings spreuke (vgl. $1: 1 ; 10: 1 ; 22: 17 ; 24: 23 ; 25: 1 ; 30: 1 ; 31: 1$ ) om die boek in onderafdelings te verdeel. Hierdie opskrifte verwys na persone wat op een of ander wyse aan die versamelings verbind is. Sommige verklaarders verkies om groter eenhede waarin meer as een "opskrif" voorkom, saam te groepeer (vgl. Farmer, 1991:1516 se vierdeling en Fox, 2000:5 se sesdeling), terwyl ander elke opskrif sien as 'n onderafdeling met verdere subverdelings (vgl. Kidner, 1964:22 se sewedeling en Clifford, 1999:1-2 wat nege onderafdelings onderskei). McKane (1970:262, 413, 643) stel 'n drieledige indeling voor, gegrond op die literatuursoorte in die boek, alhoewel hy hom in die verdere bespreking van hierdie drie literatuursoorte ook deur die "opskrifte" in die boek laat lei. ${ }^{9}$

Hierbo is gemeld dat die grootste deel van die boek Spreuke (hoofstukke 10-29) saamgestel is uit kort aforismes. Die langer leerdigte wat hierdie gedeelte omraam (1-9 en 30-31) vorm moontlik deel van die redaksieproses (vgl. Whybray, 1994a:159 e.v.), alhoewel die materiaal op sig self nie later gedateer hoef te word nie. 'n Merkbare kontras tussen Spreuke 30-31 en die voorafgaande, is dat die laaste twee hoofstukke van die boek blykbaar van buite Israel

7 Die gebruik om na jaartalle te verwys as voor of na Christus (v.C./n.C.) is besig om binne akademiese konteks in onbruik te raak vanweë onder andere die problematiek rondom die geboortejaar van Christus, asook die kulturele (Westers-Christelike) geladenheid van die uitdrukking. Die algemeen aanvaarde Engelse uitdrukking Before Common Era (BCE) word in hierdie artikel weergegee as "voor Huidige Era" (afgekort as vHE).

$8 \quad$ Met verwysing na 1 Konings 4:29-31 merk Clifford (1999:3) op dat Salomo "as king ... would have collected, sponsored, or possibly even written, various kinds of writing".

$9 \quad$ McKane (1970:11) onderskei ook met betrekking tot die literatuursoort waarna hy verwys as sentence literature, ' $n$ verdere drieledige klassifikasie. 
afkomstig was, indien gelet word op die name en herkoms van Agur en Lemuel. In hierdie artikel word die aandag veral bepaal by hierdie redaksionele raamwerk (Whybray, 1994a:159). In die "openingsraam" (1-9) vervul Spreuke 9 'n belangrike funksie. Whybray (1994a:43) wys op die konsensus wat bestaan dat hierdie hoofstuk 'n effense wysiging openbaar wat betref tradisie, indien dit vergelyk word met Spreuke 1-8. Meinhold (1991:150) is selfs meer uitgesproke wanneer hy melding maak van manches Sondergut wat in hierdie laaste hoofstuk van die inleidende gedeelte van die boek aangetref word, asook die belang van hierdie hoofstuk vir die struktuur van die boek in die geheel (vgl. Whybray, 1994a:45). In die volgende afdeling word die aandag in die besonder by hierdie hoofstuk bepaal.

\section{3. 'n Struktuurvoorstel vir Spreuke 9}

\subsection{Bestaande redaksie-historiese voorstelle}

In Spreuke 9 is die mees opvallende kenmerk die personifikasie van onderskeidelik wysheid en dwaasheid as vroue wat aan die begin (v. 1-6) en einde (v. 13-18) van die hoofstuk voorkom en wat die hoofstuk sodoende omraam. Alhoewel daar verklaarders is wat dié deel oor dwaasheid (v. 13-18) as 'n later byvoeging sien (vgl. Goldingay, 1977:90), vorm hierdie buitenste komponente van die hoofstuk volgens ander verklaarders 'n klimaks vir die hele voorafgaande inleiding tot die boek (1:8-8:36). Whybray (1994a:44) laat hom soos volg uit oor die rol van die personifikasie aan die begin en einde van die hoofstuk:

Certainly their intention was to bring the earlier teaching to a climax and to leave readers with a vivid and unforgettable impression of the choice which they have to make between 'life' and 'death'.

Vir ' $\mathrm{n}$ bespreking van die ooreenkomste en opvallende verskille tussen hierdie twee personifikasies, kan die standaard kommentare geraadpleeg word (vgl. Meinhold, 1991:150-151; Whybray, 1994b:140; Murphy, 1998:57; Clifford, 1999:130). Die volgende opsomming is vir die doeleindes van hierdie artikel voldoende:

Wat die ooreenkomste betref, is dit duidelik dat:

- wysheid en dwaasheid as vroue gepersonifieer word (v. 1, 13);

- albei vroue het 'n eie "huis" (v. 1, 14); en 
- albei rig 'n uitnodiging aan dieselfde gehoor (vgl. v. 4, 16). ${ }^{10}$

Wat die verskille betref, is die volgende duidelik:

- die algemene kontras wat tussen wysheid en dwaasheid geskep word;

- wysheid is aktief, terwyl dwaasheid passief uitgebeeld word (v. 1$2,13-14)$;

- die spyskaart van die twee "bankette" verskil aansienlik (v. 5, 17); en

- wysheid lei na die lewe, maar dwaasheid na die dood (v. 6, 18).

Die impak van die klimaks van hierdie personifikasies (wysheid = lewe; dwaasheid = dood), word volgens sommige verklaarders ietwat getemper deur die (sekondêre) toevoeging van verse 7-12 (Fox, 2000:306; Whybray, 1994b:141). Hierdie artikel wil juis wys op die opvallende struktuur en belangrike funksie van hierdie gedeelte. Alhoewel daar al enkele positiewe opmerkings oor hierdie gedeelte gemaak is (bv. Meinhold, 1991:155-158), beskou die meeste verklaarders hierdie verse nie as 'n eenheid nie, hoofsaaklik vanweë die diverse inhoud daarvan (vgl. Whybray, 1994a:45-48). Daar bestaan verder ' $\mathrm{n}$ redelike mate van eenstemmigheid dat vers 10 ongemaklik inpas in hierdie gedeelte. Fox (2000:307) meld "... v 10 seems to have originated separately from vv 7-9" en meen verder dat vers 11 ook nie in hierdie "toegevoegde" gedeelte tuishoort nie (Fox, 2000:299). Hy betoog, sonder om bewyse aan te voer, "this verse directly reinforces $\vee 6$ and was its original continuation". In sy kommentaar op hierdie gedeelte laat Fox hom nie lei deur die huidige vorm van die teks nie, maar hy lei betekenis eerder uit die historiese redaksionele proses af. Hy verplaas dus bloot vers 11 na sy "oorspronklike posisie", direk na vers 6 .

Clifford (1999:102) slaan dieselfde koers in, maar wend 'n poging aan om sy wysiging van die finale teks te motiveer: "We transfer v. 11 to after v. 6 . The pronoun in the phrase 'though me' in v. 11 has no antecedent in its present placement." Hierdie emendasievoorstelle verreken egter nie die opmerking van Whybray (1994a:46) nie, naamlik dat verse 8, 9, 11, 12 tot die tweede persoon enkelvoud gerig word, terwyl verse 5 en 6 , waartoe vers 11, volgens Fox en Clifford, redaksie-histories tuishoort, albei tot die

In die Hebreeus is vers 16 'n verbatim herhaling van vers 4. 
tweede persoon meervoud gerig word. Fox (2000:303) se struktuurvoorstel vir Spreuke 9 vertoon voorts geforseerd, omdat hy die rede vir die aanneming van wysheid se uitnodiging, naamlik dat dit tot die lewe lei, in vers 11 vind. In vers 6 is daar egter reeds 'n duidelike verwysing na die "lewe" wat wysheid bied. Hierdie voorstelle los nie die probleem van die skynbare tempering van die twee sterk metafore aan die begin en einde van Spreuke 9 op nie. Whybray (1994a:47) verwys ook na ander emendasievoorstelle, waarin aangevoer word dat verse 7-10 oorspronklik as hoogtepunt aan die einde van die hoofstuk gestaan het as 'n "final warning to undisciplined students".

Wat al hierdie enemdasievoorstelle in gemeen het, is dat hulle nie die teks in sy huidige vorm verklaar nie. Dat Spreuke 9 in sy huidige vorm 'n redaksieproses deurgaan het, is nie in dispuut nie. Die vraag is egter of daardie redaksieproses bewustelik wou afbreuk doen aan die twee opvallende vroue-metafore. Hierdie navorser meen dat die redaksionele werk eerder tot versterking van die argument sou bydra. Dat dit hier wel die geval is, word vervolgens aangetoon deur eers te kyk na 'n struktuurvoorstel vir Spreuke 9 en dan te let op die literêre tegnieke wat aangewend word in dié hoofstuk.

\section{2 'n Teksimmanente voorstel}

In die huidige teksvorm vorm die personifikasie aan die begin en die einde van Spreuke 9 'n baie mooi balans. In sy bespreking van die struktuur in veral narratiewe tekste, merk Bar-Efrat (1980:157) op dat struktuur nie bloot arbitrêr bepaal kan word nie, maar wel aan die hand van elemente in die teks wat op vier verskillende vlakke onderskei word: die verbale vlak, die vlak van die verteltegniek, die vlak van die vertelwêreld en die vlak van die konseptuele inhoud. Hierdie opmerking kan ook op poëtiese tekste soos Spreuke 9 van toepassing gemaak word. Die element van subjektiwiteit by die bepaling van die struktuur in ' $n$ teks word verminder indien aangetoon kan word dat die struktuurvoorstel op meer as een vlak ondersteun word (Bar-Efrat, 1980:172). Gedagtig aan die verbatim herhalings in Spreuke 9:1-6 en 9:13-18,11 is dit duidelik dat daar tussen hierdie twee komponente op verbale vlak 'n strukturele ooreenkoms is. Bar-Efrat se vlak van verteltegniek, waarin die klem val op hoe die vertelling aangebied word, kan in die konteks van Spreuke 9 as poëtiese teks vervang word met die vlak van poëtiese

11 Vgl. ביתח - מרמי קרת - haar huis (v. 1, 14); (uitnooi) (vv. 3, 15); en die volledige verbatim herhaling in v. 4 en 16. 
tegniek. Die ooreenkoms tussen 9:1-6 en 9:13-18 is ook op hierdie vlak merkbaar, deurdat in albei gevalle 'n duidelike personifikasie voorkom.

Hiermee is die strukturele ooreenkomste alreeds op twee vlakke aangetoon. Dit volg dat hierdie twee gedeeltes beslis struktureel verwant is. Hierdie gevolgtrekking word verder onderstreep deur 'n ooreenkoms op die vlak van die poëtiese wêreld (vertelwêreld), waarin soortgelyke gebeure (die twee bankette) by wyse van poëtiese taal uitgebeeld word.

Hierdie strukturele verwantskap is nie tot die begin en die einde van Spreuke 9 beperk nie. Byargeon (1997) het aangetoon dat Spreuke 9:7-12 'n strukturele en, meer spesifiek, 'n chiastiese eenheid vorm en dus nie bloot "an assortment of miscellaneous poems" (Bergent, 1997:84) is nie. Op die verbale vlak identifiseer Byargeon (1997:370) die volgende ooreenkomste:

- In die buitenste elemente van die chiasme word die woorde (wyse) en לץ (spotter) wat in verse 7 en 8 voorkom, in vers 12 herhaal. Hierdie herhaling vertoon op sigself 'n chiastiese (abb'a') patroon deurdat לץ wat in verse 7 en 8 eerste genoem word, laaste in vers 12 voorkom, terwyl die omgekeerde geld van חכם.

- Die tweede element van die chiasme word volgens Byargeon יסף 1997:370) gevorm deur die herhaling van die werkwoord (byvoeg/vermeerder) in verse 9 en 11.

- Vers 10 vorm dus die sentrum van die chiastiese konstruksie en volgens Watson (1981:147) se beredenering, die klimaks van dié gedeelte. 12

Die saamgroepering van verse 7 en 8 word ondersteun deur Whybray (1994a:46) se opmerking dat hierdie verse tot 'n indiwidu gerig word. Hierdie verse het ook die verbatim herhaling van die woorde spotter (ליץ) en bestraf (יכח - Hifil) in gemeen.

Op die vlak van die poëtiese tegniek word die struktuur nie net deur die chiasme, wat by wyse van herhaling geskep is, ondersteun nie. Die parallelismes in verse 7-9 en 11-12 ondersteun hierdie

12 Hierdie sentrale gedagte is op die vlak van die poëtiese wêreld ook chiasties gekonstrueer, deurdat die elemente soos volg in die oorspronklike gerangskik is: "die begin van wysheid" $(A)$ "is die vrees van die Here" $(B)$, "kennis van die Heilige" (B') "is insig" (A') (vgl. Watson, 1981:147). 
chiastiese konstruksie verder. In verse 7-9 word die volgende parallelismes aangetref: sinteties ( $v .7$ - verwysend na die spotter), antiteties (v. 8 - verwysend na die kontras tussen die spotter en die wyse), en weer sinteties (v. 9 - verwysend na die wyse). Fox (2000:307) lees te veel in die parallelle konstruksie van vers 7 in wanneer hy opmerk dat die tweede deel van die vers, die waarskuwing, die eerste deel "intensifiseer". Parallelismes is eie aan Hebreeuse poësie en die herhalende patrone in die tweede reël van so ' $n$ konstruksie is nie noodwendig ' $\mathrm{n}$ aanduiding van intensifering nie (vgl. Meinhold, 1991:17-18).13 Vers 11 is weer 'n sintetiese parallelisme (dit verwys na wysheid in die algemeen) en vers 12 is ' $n$ antitetiese parallelisme, waarin die wyse en die spotter gekontrasteer word. Hierdie parallelle konstruksies skep op die vlak van die poëtiese wêreld 'n kontras tussen die karakters van die wyse en dié van die dwase spotter. Die afwisseling van hierdie karakters ondersteun die chiastiese struktuur op die volgende wyse: spotter $(a-v$. 7-8a), wyse (b-v. 8b-9), wyse (b'- v. 11-12a), spotter (a' - v. 12b). Vers 10 staan weereens uit as sentrale gedagte, wat volgens Watson (1981:147) 'n klimaks vorm.

Die argument tot dusver het, met verwysing na twee van die vlakke wat Bar-Efrat onderskei, 'n struktuurvoorstel vir Spreuke 9 gemaak. Dit kan soos volg saamgevat word:

- Wysheid as vrou (v. 1-6) (A) [Wysheid se banket]

o Spotter en Wyse (v. 7-9) (B) [die optrede teenoor spotter en wyse]

- Sentrale gedagte (klimaks) (v.10) (X) [die weg na Wysheid]

o Wyse en Spotter (v. 11-12) (B') [die gevolge van Wysheid en spottery]

- Dwaasheid as vrou (v. 13-18) (A') [Dwaasheid se banket]

Selfs op 'n derde vlak, naamlik konseptuele inhoud, vorm hierdie gedeeltes deel van die groter struktuurpatroon in Spreuke 9. Die

13 Fokkelman (2001:75) is oortuig dat die funksie van 'n parallelisme verder strek as die estetiese. Hy wys daarop dat by parallelismes, waar die swaartepunt in die tweede kolon voorkom, die funksie daarvan kan wees om die eerste kolon te "expand ... intensify ... underline ... [or] embellish". Dit is egter moeilik om op grond van Fokkelman (2001:74-75) se kriteria sonder twyfel te stel dat Spreuke 9:7 'n geval is waar die swaartepunt wel in die tweede kolon voorkom. Ander outoriteite op die gebied van poësie sien 'n parallelisme (contra Fokkelman) bloot as "... the basic aesthetic principle of poetic utterance" (Evans, 1986:182). 
konseptuele inhoud is hierbo in blokhakies aangedui, byvoorbeeld "[Wysheid se banket]".

Hierdie voorstel vanuit 'n strukturele perspektief beklemtoon vers 10 as die duidelike speerpunt of klimaks van die hoofstuk. In hierdie hoofstuk word Wysheid en Dwaasheid in verskillende gedaantes gekontrasteer, by wyse van wat Watson (1981:137) tipeer as 'n "large scale chiasmus". Hierdie kontras maak dit duidelik dat wysheid ' $n$ beter alternatief as dwaasheid is - nie bloot wat betref die huidige optrede (v. 7-9) en die korttermyngevolge nie (v. 11-12), maar ten diepste omdat dit lei na die lewe (v. 6) en nie na die dood nie (v. 18) (vgl. Byargeon, 1997:372-374). Die vraag wat ontstaan nadat hierdie kontras aangedui is, is waar wysheid dan gevind kan word. Hierdie vraag word reg in die middel van 'n struktuur beantwoord wat herinner aan wat Watson (1981:130) beskryf as "chiastiese pentacola": wysheid behels die "vrees van die Here" en "kennis van die Heilige" (v. 10).

Die enigste probleem wat nie heeltemal by wyse van hierdie voorstel opgelos is nie, is die antesedent van die woord(e) "in/deur my" (בי) aan die begin van vers 11 . Hierbo is daarop gewys dat sommige verklaarders hierdie voorsetsel op redaksie-historiese gronde verbind met die uitnodiging van wysheid in verse 5 en 6 . In die konteks van die hoofstuk in sy huidige vorm bestaan ook ander moontlikhede. In verse $8 \mathrm{~b}$ en 9 staan die saak van wysheid steeds sentraal, alhoewel nie in gepersonifieerde vorm nie. Hierdie verse wys op die optrede teenoor 'n wyse persoon en dat hierdie optrede lei tot 'n toename in wysheid. Vers 11 en 12a bou voort op hierdie positiewe gevolge van die wysheid, wat na aanleiding van die optrede in verse $8 \mathrm{~b}$ en 9 verwerf is. Die chiastiese wyse waarop hierdie deel gekonstrueer is (v. 7-9 [spotter, wyse] vis-à-vis v. 11-12 [wyse, spotter]), verleen verdere ondersteuning aan hierdie voorstel rondom die woorde "in/deur my". Hierdie woord(e) in vers 11 verwys dus terug na vers 9 .

Die chiastiese struktuur wat in Spreuke 9 blootgelê is, is nie bloot van estetiese belang nie (Radday, 1981:51). Radday (1981:51) wys daarop dat 'n chiastiese struktuur beskou kan word as "a key to meaning" en dat die skrywers of redaktors van die Bybelteks 'n hoofgedagte ("main idea, the thesis") dikwels in die middel van 'n chiasme geplaas het. In die volgende afdeling word verder gelet op hierdie hoofgedagte in Spreuke 9, asook die belang van hierdie chiasties gekonstrueerde hoofstuk vir die res van die boek. 


\section{Die funksie(s) van die chiasme in Spreuke 9}

Meinhold (1991:43) lê 'n duidelike verband tussen die klimaks in Spreuke 9 en die eerste hoofstuk van die boek, wanneer hy opmerk dat Spreuke 1:1-7 en Spreuke 9:7-12 'n raam rondom hierdie hoofdeel van die boek (Spr. 1-9) vorm. Ander verklaarders wys ook daarop dat wat hierbo geïdentifiseer is as die sentrale vers in Spreuke 9 (vers 10), teruggryp na Spreuke 1:7 (vgl. Whybray, 1994:146; Fox, 2000:308; Murphy, 1998:58). Die motto rakende die vrees van die Here vorm op hierdie wyse 'n inclusio, waardeur die begin en die einde van die inleidende deel van die boek Spreuke met mekaar in verband gebring word.

Die voorstel wat vervolgens gemaak word, probeer aandui dat Spreuke 9 nie net verband hou met Spreuke 1 nie, maar ook met die laaste hoofstuk van die boek (Spr. 31). Hierdie verband word op die vlak van die poëtiese wêreld bewerkstellig deur die vroulike personifikasie in Spreuke 9. Op die vlak van die poëtiese tegniek maak die chiastiese struktuur van Spreuke 9 hierdie suggestie moontlik.

Daar is reeds genoem dat in Spreuke 31 langer leerdigte, soortgelyk aan die leerdigte in Spreuke 1-9, voorkom. Camp (1985:186-191) het in detail aangetoon hoe vroulike beelde in Spreuke 1-9 en Spreuke 31 die begin en einde van hierdie boek by wyse van inclusio saambind. Die huidige voorstel sluit aan by Camp se werk, maar fokus in meer detail op Spreuke 9. Die gedagte wat sentraal staan in Spreuke 9, naamlik "die vrees van die Here" (יראת יהוה 9:10), word in Spreuke 31:30 pertinent in verband gebring met die voortreflike vrou. Dit is opvallend dat vrouekarakters in Spreuke 31, soos in Spreuke 9, weer sterk op die voorgrond tree. Daar is die moeder van Lemuel wat haar seun, 'n koning, waarsku teen die gevare van vroue en drank (Spr. 31:1-9). In die konteks van Fox (2000:305-306) se siening aangaande die sosio-kulturele agtergrond van die twee bankette in Spreuke 9, naamlik dié van 'n Griekse simposium, kan dit wees dat Spreuke 31:1-9 aansluiting vind by Spreuke 9:13-18 en meer spesifiek by wyse van 'n simposium van dwase. Fox (2000:305) meld ook dat hierdie simposia, wat hoofsaaklik om drank gesentreer het, soms verval het in "inebriation and sexual license ... directed by a symposiarch, sometimes called 'king'”. Die ooreenkoms tussen hierdie beskrywing enersyds, en die waarskuwings in Spreuke 31:1-9 andersyds, is op die vlak van die poëtiese wêreld duidelik. 
Die ander vrouekarakter in Spreuke 31 word in 'n baie positiewe lig geteken. Sy is die sogenaamde "voortreflike vrou" wat in Spreuke 31:10-31 by wyse van 'n akrostiese gedig beskryf word. Bo en behalwe die algemene ooreenkoms tussen hierdie karakter en die vrouekarakters in Spreuke 1-9, is daar 'n spesifieke ooreenkoms tussen Spreuke 31:10-31 en Spreuke 9. Whybray (1994a:161) vat dit soos volg saam:

In 9.1 Wisdom builds her house; in 31:10-31 the house is already happily and successfully established ...

Die ooreenkoms tussen hierdie voortreflike vrou (31:10-31) en vrou Wysheid (9:1-6) kan op die vlak van die poëtiese wêreld aangetoon word, deur te let op die uitbeelding van albei se aktiwiteite. Hierbo is gewys op die kontras tussen die passiewe vrou Dwaasheid en die aktiewe vrou Wysheid in Spreuke 9. In Spreuke 31:10-31 vind vrou Wysheid in hierdie opsig haar komplement. Op verbale vlak is daar verdere ooreenkomste tussen hierdie gedeeltes op te merk. Albei vroue verrig die werk in "haar huis" (ביתה) - 9:1; 31:27), albei het "diensmeisies" (נערתיה - 9:3; 31:15), die een vergestalt "wysheid", die ander verwoord "wysheid" (חכמות) - 9:1; $-31: 26)$; Oחכמה van hierdie ooreenkomste op die verbale vlak en die vlak van die poëtiese wêreld, kan 'n strukturele verwantskap tussen Spreuke 9 en Spreuke 31 aangetoon word. Hierdie verwantskap is op 'n chiastiese wyse gestruktureer. Dit kan soos volg weergegee word:

- Uitnodiging van vrou Wysheid (9:1-6) (A)

o Uitnodiging van vrou Dwaasheid (9:13-18) (B)

o Waarskuwing teen 'n dwase simposium (31:1-9) (B')

- Optrede van die wyse vrou (31:10-31) (A')

Vanuit die voorafgaande word die volgende oorkoepelende en samebindende struktuurvoorstel met betrekking tot die boek Spreuke gemaak:

- Die inleidende gedeelte van die boek (Spr. 1 - 9) word rondom die motto "die begin van wysheid is die vrees van die Here" $(1: 7 ; 9: 10)$ saamgebind.

o Die chiastiese wyse waarop Spreuke 9 gestruktureer is, kontrasteer wysheid en dwaasheid op so 'n wyse dat die leser graag wysheid wil bekom.

- Die sentrale deel van die boek (Spr. 10-30) bied praktiese advies van uiteenlopende aard oor hoe om wysheid te verkry en wys op te tree. 
- Die laaste hoofstuk van die boek (Spr. 31) sluit die geheel sinvol af, deur weer terug te verwys na Spreuke 9 en die karakters en temas wat daar aan die orde gestel is.

o Die bestudering van Spreuke 9 en 31 op die verbale vlak en die vlak van die poëtiese wêreld toon 'n chiastiese konstruksie.

o Spreuke 31:30 verwys na 'n gedeelte van die motto, wanneer daarvan melding gemaak word "om die Here te vrees".

\section{Slot}

Whybray (1994a:46-47) het met betrekking tot Spreuke 9 opgemerk dat:

[m] uch scholarly ingenuity has been expended in attempts to account for the presence of this material in its present position, to explain the relationships of these verses to one another, and to show that they have wider contextual relationships connected with the redaction of the book of Proverbs as a whole.

Hierdie artikel hoort stellig tuis onder dieselfde noemer. Daar is gepoog om verder te gaan as die bestaande voorstelle met betrekking tot hierdie hoofstuk, deur spesifiek vanuit 'n strukturele perspektief te let op nuwe moontlikhede. Die slotsom is dat die chiastiese struktuur van Spreuke 9 'n aanvullende bydrae lewer tot die bestaande voorstelle rondom die struktuur en die eenheid van die boek Spreuke.

\section{Geraadpleegde bronne}

BAR-EFRAT, S. 1980. Some observations on the analysis of structure in biblical narrative. Vetus Testamentum, 30(2):154-173.

BARTON, J. 1996. Reading the Old Testament: method in biblical study. 2nd ed. Louisville: Westminster John Knox.

BERGENT, D. 1997. Israel's wisdom literature: a liberation-critical reading. Minneapolis: Fortress.

BYARGEON, R.W. 1997. The structure and significance of Prov 9:7-12. Journal of the Evangelical Theological Society, 40(3):367-375.

CAMP, C. 1985. Wisdom and the feminine in the book of Proverbs. Sheffield: Almond.

CLIFFORD, R.J. 1999. Proverbs: a commentary. Louisville: Westminster John Knox. (OTL series.)

EAGLETON, T. 1983. Literary theory: an introduction. Oxford: Blackwell.

EVANS, R.O. 1986. Parallelism. (In Preminder, A., ed. The Princeton handbook of poetic terms. Princeton: Princeton University Press. p. 182-183.)

FARMER, K.A. 1991. Who knows what is good? A commentary on the books of Proverbs and Ecclesiastes. Grand Rapids: Eerdmans. (ITC series.) 
FOKKELMAN, J.P. 2001. Reading biblical poetry: an introductory guide. (Translated by I. Smit.) Louisville: Westminster John Knox.

FOX, M.V. 2000. Proverbs 1-9: a new translation with introduction and commentary. New York: Doubleday. (AB series.)

GOLDINGAY, J. 1977. Proverbs V and IX. Revue Biblique, 84:80-93.

KIDNER, D. 1964. The Proverbs: an introduction and commentary. Leicester: IVP. (Tyndale Series.)

McKANE, W. 1970. Proverbs: a new approach. London: SCM. (OTL Series.)

MEINHOLDT, A. 1991. Die Sprüche. Teil 1: Sprüche Kapitel 1-15. Zürich: Theologisher Verlag. (Zürcher Bibelkommentare.)

MUILENBURG, J. 1969. Form criticism and beyond. Journal of Biblical Literature, 88(1):1-18.

MURPHY, R.E. 1998. Proverbs. Nashville: Thomas Nelson. (WBC series, 22.)

RADDAY, Y.T. 1981. Chiasmus in biblical narrative. (In Welch, J.W., ed. Chiasmus in antiquity: structures, analyses, exegesis. Hildesheim: Gerstenberg. p. 50-117.)

TRIBLE, P. 1994. Rhetorical criticism: context, method, and the book of Jonah. Minneapolis: Fortress. (Guides to Biblical Scholarship: Old Testament Series.)

WATSON, W.G.E. 1981. Chiastic patterns in biblical Hebrew poetry. (In Welch, J.W., ed. Chiasmus in antiquity: structures, analyses, exegesis. Hildesheim: Gerstenberg. p. 118-168.)

WELCH, J.W., ed. 1981. Chiasmus in antiquity: structures, analyses, exegesis. Hildesheim: Gerstenberg.

WHYBRAY, R.N. 1994a. The composition of the book of Proverbs. Sheffield: JSOT.

WHYBRAY, R.N. 1994b. Proverbs. Grand Rapids: Eerdmans. (NCB series.)

WHYBRAY, R.N. 1995. The book of Proverbs: a survey of modern study. Leiden: Brill.

\section{Kernbegrippe:}

Boek Spreuke

eenheid van die boek Spreuke

Spreuke 9

struktuur

\section{Key concepts:}

Book of Proverbs

Proverbs 9

structure

unity of the book of Proverbs 